\title{
Common mental disorders and sociodemographic characteristics: baseline findings of the Brazilian Longitudinal Study of Adult Health (ELSA-Brasil)
}

Maria A. Nunes, ${ }^{1}$ Andréa P. Pinheiro, ${ }^{1}$ Marina Bessel, ${ }^{1}$ André R. Brunoni, ${ }^{2}$ Andrew H. Kemp, ${ }^{2,3,4}$ Isabela M. Benseñor, ${ }^{2}$ Dora Chor, ${ }^{5}$ Sandhi Barreto, ${ }^{6}$ Maria I. Schmidt ${ }^{1}$

${ }^{1}$ Universidade Federal do Rio Grande do Sul, Porto Alegre, RS, Brazil. ${ }^{2}$ Hospital Universitário, Universidade de São Paulo, São Paulo, SP, Brazil. ${ }^{3}$ School of Psychology, Faculty of Science, University of Sydney, Sydney, New South Wales, Australia. ${ }^{4}$ Discipline of Psychiatry, Northern Clinical School, Faculty of Medicine, University of Sydney, Sydney, New South Wales, Australia. ${ }^{5}$ Escola Nacional de Saúde Pública, Fundação Oswaldo Cruz, Rio de Janeiro, RJ, Brazil. ${ }^{6}$ Universidade Federal de Minas Gerais, Belo Horizonte, MG, Brazil.

\begin{abstract}
Objective: To assess the prevalence of common mental disorders (CMD) and the association of CMD with sociodemographic characteristics in the Brazilian Longitudinal Study of Adult Health (ELSABrasil) cohort.

Methods: We analyzed data from the cross-sectional baseline assessment of the ELSA-Brasil, a cohort study of 15,105 civil servants from six Brazilian cities. The Clinical Interview Schedule-Revised (CIS-R) was used to investigate the presence of CMD, with a score $\geqslant 12$ indicating a current CMD (last week). Specific diagnostic algorithms for each disorder were based on the ICD-10 diagnostic criteria. Prevalence ratios (PR) of the association between CMD and sociodemographic characteristics were estimated by Poisson regression.

Results: CMD (CIS-R score $\geqslant 12$ ) was found in $26.8 \%$ (95\% confidence intervals [95\% Cl] 26.1-27.5). The highest burden occurred among women (PR 1.9; $95 \% \mathrm{Cl} 1.8-2.0)$, the youngest (PR 1.7; $95 \% \mathrm{Cl}$ 1.5-1.9), non-white individuals, and those without a university degree. The most frequent diagnostic category was anxiety disorders (16.2\%), followed by depressive episodes $(4.2 \%)$.

Conclusion: The burden of CMD was high, particularly among the more socially vulnerable groups. These findings highlight the need to strengthen public policies aimed to address health inequities related to mental disorders.
\end{abstract}

Keywords: Common mental disorders; depression; anxiety; low and middle-income countries; mental health

\section{Introduction}

Non-communicable diseases (NCDs) are a major health priority in Brazil, where $72 \%$ of all deaths were attributable to NCDs in 2007. They are also the main source of disease burden (14\%), with neuropsychiatric disorders being the single largest contributor, mostly due to the chronically disabling nature of mental disorders. ${ }^{1-3}$

Among these disorders, depression and anxiety disorders (AD), often referred to as common mental disorders (CMD), signal a breakdown in normal functioning and manifest as a mixture of somatic, anxiety, and depressive symptoms, frequently seen in primary care settings. The losses resulting from CMD are numerous, often contributing to psychic and somatic distress, discrimination, social isolation, low occupational and academic performance, and increased mortality. ${ }^{4}$

Correspondence: Maria Angélica Nunes, Programa de Pós-Graduação em Epidemiologia, Universidade Federal do Rio Grande do Sul, Rua Ramiro Barcelos, 2600, CEP 90035-002, Porto Alegre, RS, Brazil.

E-mail: maanunes@gmail.com

Submitted Mar 20 2015, accepted Jan 082016.
There is evidence of a high prevalence of CMD, $30 \%$ in community samples and approximately $50 \%$ in primary care samples across a range of settings in low- and middleincome countries, ${ }^{5-7}$ including Brazil..$^{8-11}$ Sociodemographic variables such as female gender and belonging to socially disadvantaged groups (education, income, and social class) remain the most consistently demonstrated risk factors for CMD. ${ }^{5,12}$ However, the data regarding age and marital status are conflicting. Additionally, no studies in Brazil have looked at the relationship between CMD and skin color/race.

Therefore, in the present study, we aimed to describe the occurrence of current CMD and corresponding diagnostic categories and their association with sex, education, skin color/race, and marital and functional status (active/retired) in Brazil.

\section{Methods}

Design and study sample

The present analysis is a cross-sectional assessment of the baseline data of the Brazilian Longitudinal Study of Adult Health (ELSA-Brasil) cohort. ELSA-Brasil, the first 
large multicenter cohort study of adult health conducted in Brazil, involves six public teaching and research institutions located in three macro-regions of Brazil (Northeast, Southeast, and South). The main objective is to investigate factors associated with the development and progression of cardiovascular diseases and diabetes. Baseline examination took place between 2008 and 2010.

All active or retired employees of the six institutions (and, in a few instances, of related educational or health institutions), of both sexes, with age between 35 and 74 years, were eligible for the study, totaling, in 2008, 52,137 potential participants. We chose civil servants as the source of the study population in order to minimize losses to follow-up related to geographical mobility. Exclusion criteria were severe cognitive or communication impairment, intention to quit work at the institution in the near future for reasons not related to retirement, and, if retired, residence outside the corresponding metropolitan area. Women with current or recent pregnancy were rescheduled, so that the first interview could take place four months after delivery. Volunteers were recruited through on-site and radio announcements, mailings, outdoor billboards, and telephone calls, the latter more commonly used to attract retirees. A randomly ordered list of employees, stratified by sex, age, and occupational category was also used to actively recruit eligible participants. Efforts were made to recruit similar proportions of men and women ( $50 \%$ each) as well as predefined proportions of age groups (15\% aged $35-44,30 \%$ aged $45-54,40 \%$ aged $55-64$, and $15 \%$ aged $65-74$ years) and occupational categories $(35 \%$ of support level with incomplete elementary school, 35\% with high school, and 30\% with higher education/teaching level). Of 16,435 who expressed interest in participation, 15,821 were preenrolled, gave written consent, responded to an initial interview, and were scheduled for the baseline examination. Only $716(4.5 \%)$ of those pre-enrolled did not complete the baseline examination. A total of 15,105 participants were enrolled, 6,887 men and 8,218 women. Further details of the cohort are described elsewhere. ${ }^{13}$

All local Institutional Review Boards approved the study protocol (Federal Universities of Bahia, Espírito Santo, Minas Gerais, and Rio Grande do Sul; Universidade de São Paulo; and Fundação Oswaldo Cruz). Written consent was obtained from all participants.

\section{$C M D$}

The Clinical Interview Schedule-Revised (CIS-R) is a structured interview for the measurement and diagnosis of non-psychotic, psychiatric morbidity developed by Lewis et al., ${ }^{14}$ which resulted from a standardization and operationalization of the original CIS developed by Goldberg ${ }^{15}$ to be used in the community and in primary care settings. The CIS-R was the main instrument used in the national psychiatric morbidity surveys in the United Kingdom ${ }^{16}$ and has been used in similar surveys around the world. 5,17-19 Several studies have reported its validity and reliability when applied to different countries and settings. ${ }^{20-23}$

The original version of the CIS-R was translated and adapted to Brazilian Portuguese and then back-translated.
These processes were also used for analysis of conceptual equivalence between items, semantics, and operational part. ${ }^{24}$

The complete CIS-R version includes 14 sections covering symptoms of CMD that are present in the last week at a level that causes distress and interference in daily activities. The symptoms are: somatic complaints (pain), fatigue, concentration and forgetfulness, sleep disturbance, irritability, worry about physical health, depression, depression ideas, worry, anxiety, phobias, panic attacks, compulsions, and obsessions. Each section begins with a number of mandatory filter questions that establish the existence of a particular symptom in the past month. The presence of a positive symptom leads to a more detailed assessment of the specific symptom in the past week (frequency, duration, severity, and time since onset) to determine a score for each section. ${ }^{24}$

Possible scores range from 0 to 4 on each section (except the section on depressive ideas, which has a maximum score of 5). Each symptom is considered clinically relevant if the score reaches two or more in the corresponding section.

The CIS-R psychiatric morbidity scale can be assessed either in a dimensional way (total score obtained by adding the scores of all 14 symptom dimensions) or in a categorical form (5 diagnostic categories). A CIS-R score $\geqslant 12$ is usually considered as the cutoff for clinically significant psychiatric morbidity. A CIS-R score $\geqslant 18$ indicates that the symptom profile is severe and thus likely to require treatment. ${ }^{14,16,23}$

Additionally, diagnosis of specific disorders is obtained by applying algorithms based on the ICD-10 diagnostic criteria $^{25}$ to the answers provided to various sections of the CIS-R. The CIS-R allows five ICD-10 diagnostic categories: generalized anxiety disorder, depressive episode, all phobias (agoraphobia, social phobia, and simple phobia), obsessive-compulsive disorder, and panic disorder. Also, a diagnosis of a mixed anxiety and depressive disorder (MADD) can be made when a CMD (i.e., CIS-R $\geqslant 12$ ) does not fulfill the criteria for any of these five ICD-10 diagnostic categories. This is in line with ICD-10 definition of MADD (F41.2), which states that "this category should be used when symptoms of anxiety and depression are both present, but neither is clearly predominant, and neither type of symptom is present to the extent that justifies a diagnosis if considered separately."

We grouped these disorders into three major groups: all types and severity levels of depressive episode, all $A D$ (general anxiety disorder, panic disorder, social anxiety disorder, phobias, and obsessive-compulsive disorders) and MADD. We also grouped participants with simultaneous depressive episode and AD.

Introductory CIS-R questions considering appetite and weight fluctuation were not included in the Elsa-Brasil questionnaire because these questions contribute neither to the scoring of a CMD nor to most specific diagnostic disorders (the only exception being depression).

\section{Demographic factors}

A detailed structured questionnaire covering sociodemographic factors was administered to each interviewee. For 
the present study, we considered the following variables: sex, age (categorized into 35-44, 45-54, 55-64, and 65-74 age groups), self-identified skin color/race category (white, brown [mixed], black, yellow, and indigenous), according to the categories used in the national census, educational level (never attended school or incomplete elementary school, complete elementary school or incomplete secondary school, complete secondary school, and university degree), marital status (married, divorced, single, widower, other [in general, having had a previous relationship]), and functional status (active or retired).

\section{Statistical analyses}

Sociodemographic characteristics were described using frequencies and percentages. The proportions of diagnostic categories were compared using the homogeneity test based on the Pearson chi-square statistic.

The prevalence and confidence interval for the categories of psychiatric morbidity (CIS-R $\geqslant 12$, depressive episode, any AD and MADD) and the co-occurrence of depressive episode and $A D$ were estimated according to sociodemographic characteristics at baseline (sex, age, self-identified skin color, educational level, marital status, and functional status). Poisson regression model with robust variance was used to estimate prevalence ratios (PR) for the association between outcome and sociodemographic characteristics adjusted for study center. All analyses were performed using SAS 9.3. The statistical tests were two-sided at significance level of $5 \%$.

\section{Results}

A total of 15,105 participants were enrolled, 6,887 men and 8,218 women.

Table 1 presents demographic characteristics. Of the total sample, 4,039 (26.8\%) participants had a CIS-R score $\geqslant 12$, indicating current CMD, and $13 \%$ had a CIS-R score $\geqslant 18$, indicating the presence of a more severe level of CMD, likely to require treatment. Table 1 also shows that CMD was more frequent among females than males (33.8 and $18.4 \%$ respectively), among younger than older participants ( 30.3 and $17.9 \%$ respectively), among those with less education compared with those with more education (27.9 and $22.5 \%$ respectively), and among those who self-identified as indigenous, black, or brown compared with those who self-identified as white (36.3, $31.9,30.9$, and $23.3 \%$, respectively). CMD was more common among participants with a previous relationship, widowed, divorced, and single compared with those who were married $(34.5,33.2,33.3,25.8$, and $24.5 \%$ respectively).

The most common symptom was worry, with a prevalence of $41.2 \%$. Other symptoms were also common, such as fatigue $(33.9 \%)$, sleep difficulty $(33.8 \%)$, and anxiety $(25.3 \%)$. Compulsions, phobias, and panic were the least common symptoms, with frequencies below $10 \%$. All symptoms occurred more frequently in women (Table 2).

As seen in Table $3, A D$ was the most frequent diagnostic category $(16.2 \%)$, followed by MADD $(12.7 \%)$, depressive episode (4.2\%), and co-occurrence of depressive episodes and $A D(3 \%)$. The prevalence of these psychiatric diagnoses was higher among women and among younger, less educated, and non-white participants. The same pattern was observed when considering the co-occurrence.

To evaluate the associations of CMD and their specific disorders with sex, age, educational attainment, and skin color/race, taking into account the simultaneous presence of these factors, we conducted Poisson regression models with robust variance (Table 4). In the fully adjusted model, similar associations were observed: the frequency of $\mathrm{CMD}$ was $90 \%$ higher in women than men (PR $=1.9[95 \%$ confidence interval $\{95 \% \mathrm{Cl}\} 1.8-2.0]), 70 \%$ higher in younger participants (35-44 years) $(\mathrm{PR}=1.7[95 \% \mathrm{Cl}$ 1.5-1.9]) than older participants, $50 \%$ higher in those with less education ( $\mathrm{PR}=1.5[95 \% \mathrm{Cl} 1.4-1.7])$ than those with college education, and 50,20 , and $10 \%$ higher respectively in those who self-identified as indigenous, brown (mixed) or black (PR = 1.5 [95\% Cl 1.2-1.8]; PR = $1.2[95 \%$ $\mathrm{Cl} 1.1-1.3] ; \mathrm{PR}=1.1[95 \% \mathrm{Cl} 1.1-1.2]$ ) than in whites.

A similar pattern of associations was also observed with regard to the specific diagnostic categories and with regard to the co-occurrence of anxiety and depressive disorders in fully adjusted models: all diagnostic categories were more frequent in women, in those who selfidentified as brown (mixed) or black skin color/race, those aged less than 55 years, those who reported marital status as "previous relationship," and those with lower educational. Of note, the co-occurrence of depressive episode with $A D$ was more strongly associated with educational attainment than the remaining disorder categories.

\section{Discussion}

Our results showed that about a quarter of the participants $(26.8 \%)$ reported symptoms, half of them meeting ICD-10 criteria for a psychiatric diagnosis. These findings, derived from a large and comprehensive study including 15,105 civil servants from selected universities or research institutes, ELSA-Brasil, ${ }^{26}$ were similar to those derived from the Megacity Mental Health Survey, ${ }^{27}$ carried out in a probabilistic sample of 5,037 adult residents in São Paulo, in which $30 \%$ of participants were classified as having CMD 12 months prior to the interview. Our findings are also similar to those of a cross-sectional study in Santiago, Chile, in which $26.7 \%$ of participants had scores indicating the presence of current CMD. ${ }^{5}$

We also found that the burden of CMD lies predominantly among those in a less advantageous social position. The earlier findings from Chile also found higher prevalence among women and among the less educated, unemployed, or divorced, those with lower socioeconomic status, and those parenting alone. ${ }^{5}$ More recently, Skapinakis et al., ${ }^{19}$ based on a nationally representative general population sample from Greece, also reported associations between CMD and female gender, being divorced or widowed, having low educational status, and being unemployed.

Of note, in urban areas of England, the prevalence of CMD was lower $(15 \%),{ }^{28}$ although a similar instrument 
Table 1 Sociodemographic characteristics of the sample and frequency of common mental disorders as defined by an elevated CIS-R score, ELSA-Brasil, 2008-2010 ( $\left.n=15,105^{\star}\right)$

\begin{tabular}{|c|c|c|c|}
\hline \multirow[b]{2}{*}{ Baseline characteristics } & \multirow[b]{2}{*}{ n (\%) } & \multicolumn{2}{|c|}{ CIS-R score $\geqslant 12$} \\
\hline & & $\mathrm{n}(\%)$ & $95 \% \mathrm{Cl}$ \\
\hline \multicolumn{4}{|l|}{ Sex } \\
\hline Men & $6,887(45.6)$ & $1,265(18.4)$ & $17.5-19.3$ \\
\hline Women & $8,218(54.4)$ & $2,774(33.8)$ & $32.8-34.8$ \\
\hline \multicolumn{4}{|l|}{ Age (years) } \\
\hline $35-44$ & $3,340(22.1)$ & $1,011(30.3)$ & $28.7-31.9$ \\
\hline $45-54$ & 5,939 (39.3) & $1,752(29.5)$ & 28.4-30.7 \\
\hline $55-64$ & $4,234(28.0)$ & $991(23.4)$ & $22.1-24.7$ \\
\hline $65-74$ & $1,592(10.6)$ & $285(17.9)$ & $16.0-19.8$ \\
\hline \multicolumn{4}{|l|}{ Self-identified skin color/race } \\
\hline Black & $2,397(16.1)$ & $764(31.9)$ & $30.0-33.7$ \\
\hline Brown (mixed) & $4,202(28.2)$ & $1,297(30.9)$ & $29.5-32.3$ \\
\hline White & $7,791(52.2)$ & $1,812(23.3)$ & $22.3-24.2$ \\
\hline Yellow & $374(2.5)$ & $71(19.0)$ & $15.0-23.0$ \\
\hline Indigenous & $157(1.0)$ & 57 (36.3) & $28.7-43.9$ \\
\hline \multicolumn{4}{|l|}{ Educational level } \\
\hline Incomplete elementary school & $894(5.9)$ & $249(27.9)$ & $25.0-30.9$ \\
\hline Incomplete secondary school & $1,028(6.8)$ & $316(30.7)$ & 27.9-33.6 \\
\hline Complete secondary school & $5,233(34.6)$ & $1,686(32.2)$ & $31.0-33.5$ \\
\hline University degree & $7,950(52.7)$ & $1,788(22.5)$ & $21.6-23.4$ \\
\hline \multicolumn{4}{|l|}{ Marital status } \\
\hline Married & $9,984(66.1)$ & $2,444(24.5)$ & $23.7-25.3$ \\
\hline Divorced & $2,451(16.2)$ & $817(33.3)$ & $31.5-35.2$ \\
\hline Single & $1,545(10.2)$ & $399(25.8)$ & $23.6-28.0$ \\
\hline Widowed & $629(4.2)$ & 209 (33.2) & $29.5-37.0$ \\
\hline Other (with previous relationship) & 495 (3.3) & $170(34.5)$ & 30.3-38.7 \\
\hline \multicolumn{4}{|l|}{ Functional status } \\
\hline Active & $12,096(80.1)$ & 3,369 (27.9) & $27.1-28.7$ \\
\hline Retired & $3,009(9.9)$ & $670(22.3)$ & $20.8-23.8$ \\
\hline Total $^{\dagger}$ & $15,105(100.0)$ & $4,039(26.8)$ & $26.1-27.5$ \\
\hline
\end{tabular}

$95 \% \mathrm{Cl}=95 \%$ confidence interval; CIS-R = Clinical Interview Schedule-Revised; ELSA-Brasil = Brazilian Longitudinal Study of Adult Health

* Small differences in total number are due to missing values.

$\dagger$ CIS-R.

Table 2 Frequency of symptoms of common mental disorders, ${ }^{*}$ ELSA-Brasil, 2008-2010 $(n=15,105)$

\begin{tabular}{|c|c|c|c|c|}
\hline CIS-R symptom* & Total & Men & Women & $\operatorname{PR}(95 \% \mathrm{Cl})^{\dagger}$ \\
\hline Worry & $6,213(41.2)$ & $2,449(35.6)$ & $3,764(45.9)$ & $1.3(1.2-1.3)$ \\
\hline Fatigue & $5,118(33.9)$ & $1,423(20.7)$ & $3,695(45.0)$ & $2.2(2.1-2.3)$ \\
\hline Sleep problems & $5,093(33.8)$ & 1,975 (28.7) & $3,118(38.0)$ & $1.3(1.3-1.4)$ \\
\hline Anxiety & 3,779 (25.3) & 1,267 (18.6) & $2,512(30.9)$ & $1.7(1.6-1.8)$ \\
\hline Irritability & $3,596(23.8)$ & 1,329 (19.3) & $2,267(27.6)$ & $1.4(1.4-1.5)$ \\
\hline Concentration & $2,358(15.6)$ & $671(9.8)$ & $1,687(20.6)$ & $2.1(1.9-2.3)$ \\
\hline Worry about physical health & $2,070(13.7)$ & $828(12.0)$ & $1,242(15.1)$ & $1.3(1.2-1.4)$ \\
\hline Obsessions & $2,028(13.5)$ & $717(10.4)$ & $1,311(16.0)$ & $1.5(1.4-1.7)$ \\
\hline Depression & $1,988(13.2)$ & $663(9.6)$ & $1,325(16.1)$ & $1.7(1.5-1.8)$ \\
\hline Depressive ideas & $1,808(12.0)$ & $591(8.6)$ & $1,217(14.8)$ & $1.7(1.6-1.9)$ \\
\hline Somatic symptoms & $1,579(10.5)$ & $395(5.7)$ & $1,184(14.4)$ & $2.5(2.3-2.8)$ \\
\hline Compulsion & $1,449(9.6)$ & $604(8.8)$ & $845(10.3)$ & $1.2(1.1-1.3)$ \\
\hline Phobias & $1,162(7.7)$ & $403(5.9)$ & $759(9.3)$ & $1.6(1.4-1.8)$ \\
\hline Panic & $515(3.4)$ & $171(2.5)$ & $344(4.2)$ & $1.7(1.4-2.0)$ \\
\hline
\end{tabular}

Data presented as $\mathrm{n}(\%)$.

$95 \% \mathrm{Cl}=95 \%$ confidence interval; CIS-R = Clinical Interview Schedule-Revised; ELSA-Brasil = Brazilian Longitudinal Study of Adult Health; $\mathrm{PR}=$ prevalence ratio.

* CIS-R score $\geqslant 2$ in each section of somatic, depressive, or anxiety symptoms.

${ }^{\dagger}$ Men as the reference category. 
Table 3 Prevalence of CIS-R diagnostic categories* according to sociodemographic characteristics, ELSA-Brasil, 2008-2010

\begin{tabular}{|c|c|c|c|c|c|c|c|c|}
\hline \multirow[b]{2}{*}{ Baseline characteristics } & \multicolumn{2}{|c|}{$\begin{array}{l}\text { Depressive } \\
\text { episode }^{\dagger}\end{array}$} & \multicolumn{2}{|c|}{$A D^{*}$} & \multicolumn{2}{|c|}{$\begin{array}{c}\text { Depressive episode and } \\
\text { AD }\end{array}$} & \multicolumn{2}{|c|}{ MADD } \\
\hline & n (\%) & $95 \% \mathrm{Cl}$ & n (\%) & $95 \% \mathrm{Cl}$ & n (\%) & $95 \% \mathrm{Cl}$ & n (\%) & $95 \% \mathrm{Cl}$ \\
\hline Total & $638(4.2)$ & $3.9-4.5$ & 2,438 (16.2) & $15.6-16.7$ & $454(3.0)$ & $2.7-3.3$ & $1,919(12.7)$ & $12.2-13.2$ \\
\hline \multicolumn{9}{|l|}{ Sex } \\
\hline Men & $159(2.3)$ & $2.0-2.7$ & $762(11.1)$ & $10.3-11.8$ & $113(1.6)$ & $1.3-1.9$ & $645(9.4)$ & 8.7-10.1 \\
\hline Women & $478(5.8)$ & $5.3-6.3$ & $1,674(20.4)$ & $19.5-21.3$ & $341(4.2)$ & $3.7-4.6$ & $1,272(15.5)$ & $14.7-16.3$ \\
\hline \multicolumn{9}{|l|}{ Age (years) } \\
\hline $35-44$ & $149(4.5)$ & $3.8-5.2$ & $590(17.7)$ & $16.4-19.0$ & $103(3.1)$ & $2.5-3.7$ & $493(14.8)$ & $13.6-16.0$ \\
\hline $45-54$ & $286(4.8)$ & 4.3-5.4 & $1,050(17.7)$ & 16.7-18.7 & $202(3.4)$ & $2.9-3.9$ & 804 (13.5) & $12.7-14.4$ \\
\hline $55-64$ & $150(3.5)$ & $3.0-4.1$ & $624(14.8)$ & $13.7-15.8$ & $114(2.7)$ & $2.2-3.2$ & 476 (11.2) & 10.3-12.2 \\
\hline $65-74$ & $53(3.3)$ & $2.5-4.2$ & $174(10.9)$ & $9.4-12.5$ & $35(2.2)$ & $1.5-2.9$ & $146(9.2)$ & $7.8-10.6$ \\
\hline \multicolumn{9}{|l|}{ Self-identified skin color/race } \\
\hline Black & $114(4.8)$ & $3.9-5.6$ & $444(18.5)$ & $17.0-20.1$ & $87(3.6)$ & $2.9-4.4$ & $374(15.6)$ & 14.1-17.1 \\
\hline Brown (mixed) & $208(5.0)$ & 4.3-5.6 & 758 (18.0) & $16.9-19.2$ & $160(3.8)$ & $3.2-4.4$ & $623(14.8)$ & $13.8-16.0$ \\
\hline White & $290(3.7)$ & 3.3-4.1 & $1,128(14.5)$ & $13.7-15.3$ & $188(2.4)$ & $2.1-2.8$ & $842(10.8)$ & 10.1-11.5 \\
\hline Asian & $12(3.2)$ & $1.4-5.0$ & $49(13.1)$ & $9.7-16.5$ & $7(1.9)$ & $0.5-3.3$ & $36(9.6)$ & 6.6-12.6 \\
\hline Indigenous & $11(7.0)$ & $3.0-11.0$ & $39(24.8)$ & $18.0-31.7$ & $10(6.4)$ & $2.5-10.2$ & $22(14.0)$ & 8.5-19.5 \\
\hline \multicolumn{9}{|l|}{ Educational level } \\
\hline Incomplete elementary school & $40(4.5)$ & $3.1-5.8$ & 163 (18.3) & $15.7-20.8$ & $31(3.5)$ & $2.3-4.7$ & $103(11.5)$ & $9.4-13.6$ \\
\hline Incomplete secondary school & $60(5.8)$ & 4.4-7.3 & $190(18.5)$ & $16.1-20.9$ & $43(4.2)$ & $3.0-5.4$ & $140(13.6)$ & $11.5-15.7$ \\
\hline Complete secondary school & $288(5.5)$ & $4.9-6.1$ & $1,036(19.8)$ & $18.7-20.9$ & $220(4.2)$ & $3.7-4.8$ & 744 (14.2) & 13.3-15.2 \\
\hline University degree & $250(3.1)$ & 2.8-3.5 & $1,049(13.2)$ & $12.5-14.0$ & $160(2.0)$ & $1.7-2.3$ & $932(11.7)$ & $11.0-12.4$ \\
\hline \multicolumn{9}{|l|}{ Marital status } \\
\hline Married & $346(3.5)$ & $3.1-3.8$ & $1,441(14.4)$ & $13.8-15.1$ & $249(2.5)$ & $2.2-2.8$ & $1,226(12.3)$ & $11.6-13.0$ \\
\hline Divorced & $154(6.3)$ & $5.3-7.2$ & 527 (21.5) & $19.9-23.1$ & $108(4.4)$ & $3.6-5.2$ & 327 (13.3) & $12.0-14.7$ \\
\hline Single & $61(3.9)$ & $3.0-5.0$ & $215(13.9)$ & $12.2-15.7$ & $35(2.3)$ & $1.5-3.0$ & $214(13.9)$ & $12.1-15.6$ \\
\hline Widower & $36(5.7)$ & $3.9-7.5$ & $133(21.1)$ & $17.9-24.3$ & 27 (4.3) & $2.7-5.9$ & $90(14.3)$ & $11.6-17.1$ \\
\hline Other (with previous relationship) & $41(8.3)$ & $5.9-10.8$ & $122(24.7)$ & $20.9-28.6$ & $35(7.1)$ & 4.8-9.4 & $62(12.6)$ & $9.6-15.5$ \\
\hline \multicolumn{9}{|l|}{ Functional status } \\
\hline Active & $515(4.3)$ & $3.9-4.6$ & $2,020(16.7)$ & $16.0-17.4$ & $368(3.0)$ & $2.7-3.4$ & 1,597 (13.2) & $12.6-13.8$ \\
\hline Retired & $123(4.1)$ & $3.4-4.8$ & $418(14.0)^{\prime}$ & $12.7-15.1$ & $86(2.9)$ & 2.3-3.5 & $322(10.7)$ & $9.6-11.8$ \\
\hline
\end{tabular}

$95 \% \mathrm{Cl}=95 \%$ confidence interval; $\mathrm{AD}=$ anxiety disorder; CIS-R = Clinical Interview Schedule-Revised; ELSA-Brasil = Brazilian Longitudinal Study of Adult Health; MADD = mixed anxiety and depressive disorder.

* CIS-R diagnostic categories as defined by the ICD-10.

Mild to severe episodes.

Includes phobias, panic disorder, obsessive compulsive disorder, and generalized anxiety disorder.

(CIS-R) was used. Nevertheless, the associations they found with sociodemographic characteristics were similar to those we and others found, including studies from Greece, Chile, and Brazil. It is possible that populations living in less socioeconomically developed countries could be experiencing more distress as a result of contextual pressures in their societies.

The relationship with sociodemographic characteristics corroborates earlier findings of community-based studies. In 1999, Patel et al. ${ }^{12}$ pointed out that female gender, social, economic, and interpersonal factors are the most consistent risk factors for CMD in industrialized societies.

The higher burden of CMD in certain groups deserves interpretation. The multiple roles played by women, such as child bearing and child rearing, running the family home, caring for sick relatives, and providing for the economic needs of children, along with domestic violence, are likely to produce considerable stress. Although other factors may also play a role, such as the neuroendocrinological system, ${ }^{10}$ the vulnerability of women needs to be more widely acknowledged. ${ }^{12}$
The higher frequency of CMD in the younger age group (35-54 years) underscores previews results obtained by studies carried out in developed countries where older age is usually associated with reduced prevalence of CMD. ${ }^{29}$ This highlights an important dimension of the high burden of disease caused by mental disorders, since young and middleaged adults play a vital role in the productive economy.

Also, the higher prevalence of CMD in non-white participants in this study is consistent with previous findings suggesting that racial discrimination may augment the vulnerability to develop CMD. ${ }^{30}$ Since the associations we describe were adjusted for various sociodemographic characteristics, we may interpret that, at least in part, they result from racial or race-related problems.

We observed a frequency of symptoms that is similar to that reported in several studies from high and low income countries. $^{6,7,17}$ The presence of symptoms was much more frequent than an actual diagnosis of CMD. A higher frequency of psychiatric symptoms as compared to psychiatric disorders identified through current diagnostic classifications (ICD-10 and DSM-5) has been reported. ${ }^{31,32}$ 
Table 4 PR estimates* for the associations of elevated CIS-R score and corresponding diagnostic categories ${ }^{\dagger}$ with sociodemographic characteristics, ELSA-Brasil, 2008-2010

\begin{tabular}{|c|c|c|c|c|c|}
\hline Variables & CIS-R $\geqslant 12$ score & Depressive episode & $A D$ & Depressive episode and AD & MADD \\
\hline \multicolumn{6}{|l|}{ Sex } \\
\hline Men & 1 & 1 & 1 & 1 & 1 \\
\hline Women & $1.9(1.8-2.0)$ & $2.5(2.0-3.0)$ & $1.8(1.7-2.0)$ & $2.5(2.0-3.2)$ & $1.7(1.5-1.9)$ \\
\hline \multicolumn{6}{|l|}{ Age (years) } \\
\hline $35-44$ & $1.7(1.5-1.9)$ & $1.6(1.1-2.4)$ & $1.6(1.3-2.0)$ & $1.6(1.0-2.7)$ & $1.5(1.2-1.9)$ \\
\hline $45-54$ & $1.5(1.3-1.8)$ & $1.6(1.1-2.3)$ & $1.5(1.3-1.8)$ & $1.6(1.0-2.5)$ & $1.3(1.1-1.7)$ \\
\hline $55-64$ & $1.2(1.1-1.4)$ & $1.1(0.8-1.5)$ & $1.3(1.1-1.5)$ & $1.2(0.8-1.8)$ & $1.2(1.0-1.4)$ \\
\hline $65-74$ & 1 & 1 & 1 & 1 & 1 \\
\hline \multicolumn{6}{|l|}{ Self-identified skin color/race } \\
\hline White & 1 & 1 & 1 & 1 & 1 \\
\hline Black & $1.1(1.1-1.2)$ & $1.0(0.8-1.2)$ & $1.0(0.9-1.2)$ & $1.1(0.8-1.4)$ & $1.3(1.2-1.5)$ \\
\hline Brown (mixed) & $1.2(1.1-1.3)$ & $1.1(0.9-1.3)$ & $1.1(1.0-1.2)$ & $1.2(1.0-1.6)$ & $1.3(1.2-1.4)$ \\
\hline Yellow & $0.8(0.6-1.0)$ & $0.8(0.5-1.4)$ & $0.9(0.7-1.1)$ & $0.7(0.3-1.5)$ & $0.9(0.6-1.2)$ \\
\hline Indigenous & $1.5(1.2-1.8)$ & $1.6(0.9-3.0)$ & $1.5(1.2-2.0)$ & $2.2(1.1-4.1)$ & $1.3(0.9-2.0)$ \\
\hline \multicolumn{6}{|l|}{ Educational level } \\
\hline Incomplete elementary school & $1.5(1.4-1.7)$ & $1.9(1.4-2.7)$ & $1.7(1.5-2.0)$ & $2.2(1.5-3.3)$ & $1.1(0.9-1.4)$ \\
\hline Incomplete secondary school & $1.5(1.4-1.7)$ & $2.2(1.6-2.9)$ & $1.6(1.4-1.8)$ & $2.4(1.7-3.4)$ & $1.2(1.0-1.5)$ \\
\hline Complete secondary school & $1.4(1.3-1.4)$ & $1.7(1.4-2.0)$ & $1.4(1.3-1.6)$ & $2.0(1.6-2.5)$ & $1.1(1.0-1.3)$ \\
\hline University degree & 1 & 1 & 1 & 1 & 1 \\
\hline \multicolumn{6}{|l|}{ Marital status } \\
\hline Married & 1 & 1 & 1 & 1 & 1 \\
\hline Divorced & $1.2(1.1-1.2)$ & $1.5(1.2-1.8)$ & $1.3(1.2-1.4)$ & $1.4(1.1-1.7)$ & $0.9(0.8-1.1)$ \\
\hline Single & $0.9(0.8-1.0)$ & $1.0(0.7-1.3)$ & $0.9(0.7-1.0)$ & $0.8(0.5-1.1)$ & $1.0(0.9-1.1)$ \\
\hline Widower & $1.1(1.0-1.3)$ & $1.2(0.8-1.7)$ & $1.2(1.0-1.4)$ & $1.2(0.8-1.8)$ & $1.0(0.8-1.2)$ \\
\hline Other (with previous relationship) & $1.2(1.1-1.4)$ & $2.0(1.5-2.7)$ & $1.5(1.3-1.8)$ & $2.3(1.7-3.3)$ & $0.9(0.7-1.1)$ \\
\hline \multicolumn{6}{|l|}{ Functional status } \\
\hline Active & 1 & 1 & 1 & 1 & 1 \\
\hline Retired & $1.0(0.90-1.1)$ & $1.1(0.9-1.5)$ & $1.0(0.8-1.1)$ & $1.1(0.8-1.5)$ & $1.0(0.8-1.1)$ \\
\hline
\end{tabular}

Data presented as PR $(95 \% \mathrm{Cl})$.

$95 \% \mathrm{Cl}=95 \%$ confidence interval; $\mathrm{AD}=$ anxiety disorder; CIS-R = Clinical Interview Schedule-Revised; ELSA-Brasil = Brazilian Longitudinal Study of Adult Health; MADD = mixed anxiety and depressive disorder; PR $=$ prevalence ratio.

* Adjusted for all variables in the table.

Based on the CIS-R. Diagnostic categories as defined by the ICD-10.

Therefore, it seems that not only did we capture individuals with a more specific mental health disorder, but also those facing and reacting to stressful life circumstances, particularly since the most common psychiatric symptom observed was worry. Thus, symptoms captured by the CIS-R, if applied at the primary care level, are likely to reflect predominantly situational reactions, with just a small proportion representing diagnosable mental disorders. Most adjustment problems, such as dealing with stressors, which cause anxiety or depressed mood, are self-limited, and usually improve with time, support, and adequate orientation. In turn, a psychiatric disorder requires careful evaluation and longitudinal observation. ${ }^{32}$

Our study has some strengths, including a focus on a relatively large and well-characterized sample of civil servants from major urban areas in Brazil, being one of the largest studies in a low-/middle-income country. This study used a structured psychiatric interview (CIS-R) administered by lay interviewers who underwent intensive training and were closely supervised during the fieldwork.

Efforts were made to reduce ascertainment bias arising from cultural and clinical invalidity through careful translation and back-translation procedures. We hope to have increased the local validity of the Brazilian Portuguese version with the help of advice from an independent local psychiatrist at the final stage of translation. Previous research has shown that careful attention to translation and conceptual validity enables the use of etic instruments with reasonable confidence across cultures. ${ }^{33}$

Despite these strengths, the cross-sectional associations here reported may suffer from reverse causality, although gender and race associations are unlikely to be affected. Additionally, the exclusion of younger adults (less than 35 years of age) limits the generalizability of our findings to a broader age range. Further, our study was not planned to be representative of a defined Brazilian population, and prevalence figures can, at best, be generalized to adults with similar characteristics living and working in other Brazilian state capitals. Of note, the characteristics of our sample were similar to those of a probabilistic sample of adults living in capital cities in Brazil. ${ }^{26}$ Finally, since the CIS-R introductory questions (appetite and weight fluctuation) were not included in the questionnaire, the prevalence of depression may be slightly underestimated.

In conclusion, the burden of CMD is high, particularly in more socially vulnerable subgroups of the population. These findings draw attention to the importance of CMD for public policy, and reinforce the need to include mental 
health care in primary efforts to improve the well-being of individuals and the community.

\section{Acknowledgements}

AHK was supported by an international visiting professorship from Universidade de São Paulo (USP). The ELSABrasil baseline study was supported by the Brazilian Ministry of Health (Science and Technology Department) and the Brazilian Ministry of Science and Technology (Financiadora de Estudos e Projetos and Conselho Nacional de Desenvolvimento Científico e Tecnológico [CNPq]) (grants $01060010.00 \mathrm{RS}, 01060212.00 \mathrm{BA}, 01$ 060300.00 ES, 01060278.00 MG, 01060115.00 SP, 01 $060071.00 \mathrm{RJ})$. The funders had no role in study design, data collection and analysis, decision to publish, or preparation of the manuscript. The authors would like to acknowledge the contribution of the 15,105 participants without whom this study and those based on the ELSABrasil cohort would not have been possible.

\section{Disclosure}

The authors report no conflicts of interest.

\section{References}

1 Schmidt MI, Duncan BB, Azevedo e Silva G, Menezes AM, Monteiro CA, Barreto SM, et al. Chronic non-communicable diseases in Brazil: burden and current challenges. Lancet. 2011;377:1949-61.

2 Murray CJ, Lopez AD. Alternative projections of mortality and disability by cause 1990-2020: Global Burden of Disease Study. Lancet. 1997;349:1498-504.

3 Whiteford HA, Degenhardt L, Rehm J, Baxter AJ, Ferrari AJ, Erskine $\mathrm{HE}$, et al. Global burden of disease attributable to mental and substance use disorders: findings from the Global Burden of Disease Study 2010. Lancet. 2013;382:1575-86.

4 Goldberg D, Goodyer I. The origins and course of common mental disordersNew York: Routledge; 2005.

5 Araya R, Rojas G, Fritsch R, Acuãa J, Lewis G. Common mental disorders in Santiago, Chile: prevalence and socio-demographic correlates. Br J Psychiatry. 2001;178:228-33.

6 Shamasundar C, Murthy SK, Prakash OM, Prabhakar N, Krishna DK. Psychiatric morbidity in a general practice in an Indian city. Br Med J (Clin Res Ed). 1986;292:1713-5.

7 Hollifield M, Katon W, Spain D, Pule L. Anxiety and depression in a village in Lesotho, Africa: a comparison with the United States. $\mathrm{Br} \mathrm{J}$ Psychiatry. 1990;156:343-50.

8 Lima MS, Beria JU, Tomasi E, Conceicao AT, Mari JJ. Stressful life events and minor psychiatric disorders: an estimate of the population attributable fraction in a Brazilian community-based study. Int $\mathrm{J}$ Psychiatry Med. 1996;26:211-22.

9 Maragno L, Goldbaum M, Gianini RJ, Novaes HM, César CL. [Prevalence of common mental disorders in a population covered by the Family Health Program (QUALIS) in São Paulo, Brazil]. Cad Saude Publica. 2006;22:1639-48.

10 Gonçalves DM, Kapczinski F. [Mental disorders in a community assisted by the Family Health Program]. Cad Saude Publica. 2008:24:1641-50.

11 Fortes S, Villano LA, Lopes CS. Nosological profile and prevalence of common mental disorders of patients seen at the Family Health Program (FHP) units in Petrópolis, Rio de Janeiro. Rev Bras Psiquiatr. 2008;30:32-7.

12 Patel V, Araya R, de Lima M, Ludermir A, Todd C. Women, poverty and common mental disorders in four restructuring societies. Soc Sci Med. 1999;49:1461-71.

13 Aquino EML, Araujo MJ, Almeida M da CC, Conceicao P, Andrade CR de, Cade NV, et al. Recrutamento de participantes no Estudo Longitudinal de Saude do Adulto. Rev Saude Publica. 2013;47:10-8.
14 Lewis G, Pelosi AJ, Araya R, Dunn G. Measuring psychiatric disorder in the community: a standardized assessment for use by lay interviewers. Psychol Med. 1992;22:465-86.

15 Goldberg DP, Cooper B, Eastwood MR, Kedward HB, Shepherd M. A standardized psychiatric interview for use in community surveys. $\mathrm{Br}$ J Prev Soc Med. 1970;24:18-23.

16 Singleton N, Bumpstead R, O'Brien M, Lee A, Meltzer H. Psychiatric morbidity among adults living in private households, 2000. Int Rev Psychiatry. 2003;15:65-73.

17 Botega NJ, Pereira WA, Bio MR, Garcia Júnior C, Zomignani MA. Psychiatric morbidity among medical in-patients: a standardized assessment (GHQ-12 and CIS-R) using "lay" interviewers in a Brazilian hospital. Soc Psychiatry Psychiatr Epidemiol. 1995;30:127-31.

18 Liu SI, Mann A, Cheng A, Tjung JJ, Hwang LC. Identification of common mental disorders by general medical doctors in Taiwan. Gen Hosp Psychiatry. 2004;26:282-8.

19 Skapinakis P, Bellos S, Koupidis S, Grammatikopoulos I, Theodorakis PN, Mavreas V. Prevalence and sociodemographic associations of common mental disorders in a nationally representative sample of the general population of Greece. BMC Psychiatry. 2013;13:163-163.

20 Pez O, Gilbert F, Bitfoi A, Carta MG, Jordanova V, Garcia-Mahia C, et al. Validity across translations of short survey psychiatric diagnostic instruments: CIDI-SF and CIS-R versus SCID-I/NP in four European countries. Soc Psychiatry Psychiatr Epidemiol. 2010;45:1149-59.

21 Brugha TS, Bebbington PE, Jenkins R, Meltzer H, Taub NA, Janas M, et al. Cross validation of a general population survey diagnostic interview: a comparison of CIS-R with SCAN ICD-10 diagnostic categories. Psychol Med. 1999;29:1029-42.

22 National Center for Social Research (NatCen). Adult psychiatric morbidity survey [Internet]. Appendices and glossary. 2009 [cited 2016 Apr 11]. http://www.natcen.ac.uk/our-research/research/adultpsychiatric-morbidity-survey/.

23 Skapinakis P, Anagnostopoulos F, Bellos S, Magklara K, Lewis G, Mavreas V. An empirical investigation of the structure of anxiety and depressive symptoms in late adolescence: cross-sectional study using the Greek version of the revised Clinical Interview Schedule. Psychiatry Res. 2011;186:419-26.

24 Nunes MAA, Alves MG de M, Chor D, Schmidt MI, Duncan BB. Adaptação transcultural do CIS-R (Clinical Interview ScheduleRevised Version) para o português no Estudo Longitudinal de Saúde do Adulto (ELSA). Rev HCPA. 2011;31:487-90.

25 World Health Organization (WHO). International Classification of Diseases (ICD) [Internet]. [cited 2015 Mar 02]. www.who.int/classifications/icd/en/.

26 Iser BP, Malta DC, Duncan BB, de Moura L, Vigo A, Schmidt MI. Prevalence, correlates, and description of self-reported diabetes in Brazilian capitals - results from a telephone survey. PloS One. 2014;9:e108044-e108044.

27 Andrade LH, Wang YP, Andreoni S, Silveira CM, Alexandrino-Silva C, Siu ER, et al. Mental disorders in megacities: findings from the São Paulo megacity mental health survey, Brazil. PLoS One. 2012;7: e31879-e31879.

28 Bastos JL, Barros AJ, Celeste RK, Paradies Y, Faerstein E. Age, class and race discrimination: their interactions and associations with mental health among Brazilian university students. Cad Saude Publica. 2014;30:175-86.

29 Kessler RC, Birnbaum HG, Shahly V, Bromet E, Hwang I, McLaughlin $\mathrm{KA}$, et al. Age differences in the prevalence and co-morbidity of DSMIV major depressive episodes: results from the WHO World Mental Health Survey Initiative. Depress Anxiety. 2010;27:351-64.

30 Anselmi L, Barros FC, Minten GC, Gigante DP, Horta BL, Victora CG. [Prevalence and early determinants of common mental disorders in the 1982 birth cohort, Pelotas, Southern Brazil]. Rev Saude Publica. 2008;42:26-33.

31 Organização Mundial da Saúde (OMS). Classificação estatística internacional de doenças e problemas relacionados è saúde - CID10. [cited 2010 Nov 12]datasus.gov.br/cid10/V2008/cid10.htm.

32 American Psychiatric Association. Diagnostic and Statistical Manual of Mental Disorders, Fifth Edition (DSM-5)Arlington: American Psychiatric Publishing; 2013.

33 Das-Munshi J, Castro-Costa E, Dewey ME, Nazroo J, Prince M. Cross-cultural factorial validation of the Clinical Interview Schedule-Revised (CIS-R); findings from a nationally representative survey (EMPIRIC). Int J Methods Psychiatr Res. 2014;23:229-44. 